\title{
New developments in bone-conduction hearing implants: a review
}

This article was published in the following Dove Press journal:

Medical Devices: Evidence and Research

16 January 2015

Number of times this article has been viewed

\author{
Sabine Reinfeldt ${ }^{\prime}$ \\ Bo Håkansson' \\ Hamidreza Taghavi' \\ Måns Eeg-Olofsson ${ }^{2}$ \\ 'Department of Signals and Systems, \\ Chalmers University of Technology, \\ Gothenburg, Sweden; ${ }^{2}$ Department \\ of Otorhinolaryngology, Head \\ and Neck Surgery, Sahlgrenska \\ University Hospital, Sahlgrenska \\ Academy, University of Gothenburg, \\ Gothenburg, Sweden
}

\begin{abstract}
The different kinds of bone-conduction devices (BCDs) available for hearing rehabilitation are growing. In this paper, all BCDs currently available or in clinical trials will be described in categories according to their principles. BCDs that vibrate the bone via the skin are referred to as skin-drive devices, and are divided into conventional devices, which are attached with softbands, for example, and passive transcutaneous devices, which have implanted magnets. BCDs that directly stimulate the bone are referred to as direct-drive devices, and are further divided into percutaneous and active transcutaneous devices; the latter have implanted transducers directly stimulating the bone under intact skin. The percutaneous direct-drive device is known as a bone-anchored hearing aid, which is the BCD that has the largest part of the market today. Because of some issues associated with the percutaneous implant, and to some extent because of esthetics, more transcutaneous solutions with intact skin are being developed today, both in the skin-drive and in the direct-drive category. Challenges in developing transcutaneous BCDs are mostly to do with power, attachment, invasiveness, and magnetic resonance imaging compatibility. In the future, the authors assume that the existing percutaneous direct-drive BCD will be retained as an important rehabilitation alternative, while the transcutaneous solutions will increase their part of the market, especially for patients with bone-conduction thresholds better than $35 \mathrm{~dB}$ HL (hearing level). Furthermore, the active transcutaneous direct-drive BCDs appear to be the most promising systems, but to establish more detailed inclusion criteria, and potential benefits and drawbacks, more extensive clinical studies are needed.
\end{abstract}

Keywords: bone-conduction device, implantable, transcutaneous, percutaneous, active, passive

\section{Introduction}

Bone-conduction devices (BCDs) are used in a wide range of applications such as communication systems, language development approaches, mitigation of stuttering, audiometric investigations and finally and most importantly, in hearing rehabilitation. This review is focused on BCDs for hearing rehabilitation, where the common indications are conductive and mixed hearing loss and also single-sided deafness. These BCD devices can be non-implantable (conventional BCDs) and semi-implantable, where some part of the device is implanted. In what follows, the term implanted is used instead of semi-implanted for simplicity, as fully implanted BCDs (all parts implanted) are most likely just hypothetical and hard to implement due to the huge inherent vibration feedback problems.

Conventional BCDs were developed in the beginning of the 20 th century ${ }^{1,2}$ with a sound processor attached with spectacles, steel spring headbands, or soft headbands.
Correspondence: Sabine Reinfeldt Department of Signals and Systems, Chalmers University of Technology, SE-4I 296 Gothenburg, Sweden

$\mathrm{Tel}+46317728063$

Fax +46 3I 772 I782

Email sabine.reinfeldt@chalmers.se 
The vibrations that are produced are transmitted through the skin to the skull bone, and further to the cochlea in the inner ear, bypassing a conductive impairment in the external or middle ear. The development of the conventional BCD was a big step forward in the rehabilitation of these patients; however, the devices have some drawbacks. The static pressure on the skin needs to be high enough to transmit the vibrations to the cochlea, leaving the skin compressed, which might lead to discomfort and skin problems in the attachment area. The primary issue with conventional BCDs, applied with a headband as well as with frames of a pair of glasses, is related to the static pressure of approximately $2 \mathrm{~N}$ towards the skin and the soft tissues. ${ }^{3}$ Furthermore, the skin attenuates the high-frequency vibrations, and therefore, the sound that reaches the cochlea has a lower content of high frequencies.

In the 1960s, Per-Ingvar Brånemark discovered that bone can attach firmly on titanium (ie, titanium can be osseointegrated). ${ }^{4}$ This discovery was first used in dental implants with great success. In the late 1970s, a project started as a collaboration between Chalmers University of Technology, Sahlgrenska University Hospital, and Brånemark Osseointegration Center to develop a hearing aid attached to an integrated screw in the skull bone. ${ }^{5}$ This new percutaneous BCD was called the bone-anchored hearing aid (BAHA), and had several advantages over the conventional BCD. Most importantly, the skin was not compressed, eliminating the circulatory problems, and furthermore, when vibrations were transmitted through the screw directly to the bone instead of through the skin, the high frequencies were also preserved. This device has been improved over the years, and today (in 2014) more than 150,000 patients have been treated. ${ }^{6,7}$ The BAHA offers good hearing rehabilitation, but still there are some drawbacks associated with the skin-penetrating implant (eg, loss of osseointegration, and skin complications). ${ }^{8-13}$ The esthetical appearance is also a debated issue, although not scientifically assessed.

The success with the BAHA initiated new ideas of implantable BCDs which did not need a percutaneous implant. Instead implantable BCDs transmitted the signal transcutaneously using different techniques. Already in the 1980s, the Audiant Xomed was developed by Jack Hough et al. ${ }^{14}$ This device used an implanted magnet anchored in the temporal bone under the skin behind the ear. The Xomed's external audio processor included a magnet that was attracted to the implanted magnet. The implanted magnet was not only used for retention, the magnet was also part of the vibration transducer design, and thus the vibrations were directly transmitted to the skull bone. However, the problem with this transducer design was that the skin formed the required air gap in the transducer (air gap of size 4-5 mm due to skin thickness), which gave an output that was approximately $20 \mathrm{~dB}$ lower than the BAHA (air gap of approximately $0.1 \mathrm{~mm}) .{ }^{15}$ Because of the power issues related to large air gaps and because of skin complications related to skin compression, the Xomed device was withdrawn from the market after a couple of years.

Following the Xomed failure, there was no interest in transcutaneous implantable BCDs for many years, but during the last 10 years, several new projects have evolved with the purpose to develop transcutaneous implantable solutions. The driving forces behind this trend are to find solutions that are more esthetically appealing, and maybe most importantly, to avoid the challenges associated with permanent skin penetration used in BAHA systems. Some of the new devices are already on the market, while others are in clinical trials. The implantable BCDs can be divided into two main groups: first, "direct-drive systems" (Baha ${ }^{\circledR}$, Ponto, bone-conduction implant $[\mathrm{BCI}]$, and Bonebridge $\left.{ }^{\mathrm{TM}}\right)$, where the vibrations are transmitted directly to the skull bone; and secondly, "skindrive systems," where the vibrations are transmitted through the skin (Sophono ${ }^{\circledR}$ and Baha ${ }^{\circledR}$ Attract).

\section{Aim of study}

In this paper, all present BCDs for hearing rehabilitation, known to the authors to be available on the market or being in clinical trials, will be described. The authors have organized all BCDs into categories to increase the understanding of their principles. Middle-ear implants and direct acoustic cochlear implants do not use BC and are therefore excluded from this review.

\section{Bone-conduction devices}

To categorize all existing BCDs for hearing rehabilitation, the first division was made into "direct-drive" BCDs and "skindrive" BCDs (see Figure 1). All direct-drive BCDs transmit vibrations directly to the skull bone, not through the skin. Skin-drive BCDs transmit vibrations through the skin, and can be divided into conventional and passive transcutaneous BCDs. A similar division could be made to direct-drive $\mathrm{BCDs}$, which are divided into percutaneous and active transcutaneous devices. There is also a category of BCDs called in-the-mouth devices, which are neither direct-drive nor skin-drive BCDs, as they stimulate the ear by transmitting vibrations via a tooth and its relatively stiff root connected to the skull. 


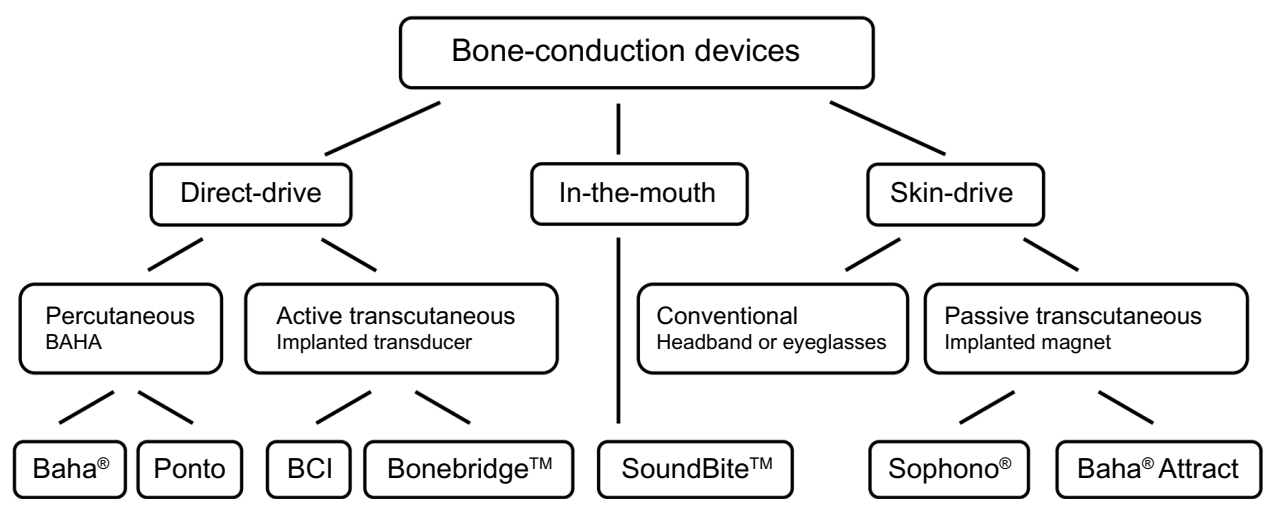

Figure I Categorization of bone-conduction devices.

Abbreviations: $\mathrm{BAHA}$, bone-anchored hearing aid; $\mathrm{BCl}$, bone-conduction implant.

This chapter describes all BCDs that are on the market and those that are approaching the market in clinical trials. More technical details of the transducer designs in these generic $\mathrm{BCDs}$ are presented by Håkansson. ${ }^{16}$

\section{Skin-drive BCDs}

All skin-drive BCDs are characterized by the fact that the vibrations are transmitted through the skin, which is kept intact. In conventional skin-drive BCDs, all components are kept outside the skin, while the passive transcutaneous skin-drive BCDs contain implanted magnet(s).

\section{Conventional skin-drive BCD}

The conventional skin-drive $\mathrm{BCD}$ was the first $\mathrm{BCD}$ on the market (see Figure 2). It is attached with a soft headband (softband), a steel spring headband, or with spectacles for glasses. Today there are a few companies that still manufacture and offer conventional devices - for example, BHM-Tech in Austria and Bruckhoff in Germany. In addition, BAHAs are sometimes used with a softband/headband instead of a titanium screw, thus behaving as a conventional skin-drive device. There are two manufacturers of BAHAs, Oticon Medical (Askim, Sweden) and Cochlear Bone Anchored

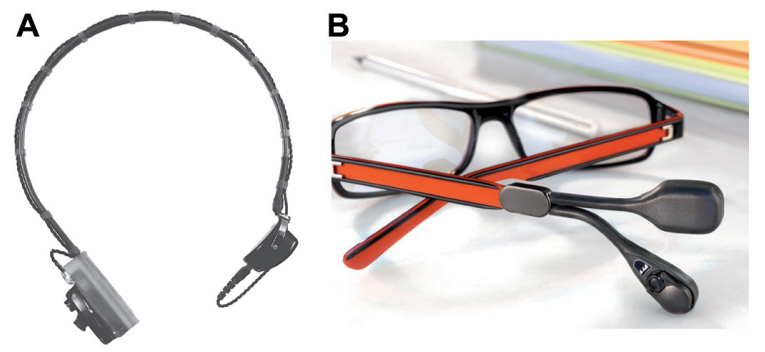

Figure 2 Conventional skin-drive bone-conduction devices, attached with (A) a steel spring headband, and (B) with frames for glasses.

Note: Images provided courtesy of (A) Starkey Hearing Technologies, (B) bruckhoff hannover gmbh.
Solutions (Mölnlycke, Sweden), where the BAHAs are also available with softband/headband application.

The use of BAHA on a softband (elastic fabric) or headband (diadem type) is a valuable method of hearing rehabilitation in children who are too young for implantation, ${ }^{17,18}$ and it is the gold standard for preoperative assessment. ${ }^{19}$ However, one should bear in mind that the final hearing improvement with a percutaneous BAHA usually is better than with a BAHA on a softband. ${ }^{20,21}$ In particular, Verstraeten et $\mathrm{al}^{22}$ have shown that the hearing sensitivity through the skin, as compared with a skin penetrating abutment, is between 8 and $20 \mathrm{~dB}$ lower in the frequency range from 1 to $4 \mathrm{kHz}$ (see Figure 3 in Verstraeten et $\mathrm{al}^{22}$ ). This is in line with results presented already in the 1980s by Håkansson et al, ${ }^{23}$ who compared the hearing thresholds using the same transducer attached first to a percutaneous implant and then to the nearby skin.

Furthermore, conventional BC is today used in communication systems of various kinds. One interesting application is the Google Glass ${ }^{24}$ that uses a BC transducer as a complementary speaker to air-conduction (AC) receivers.

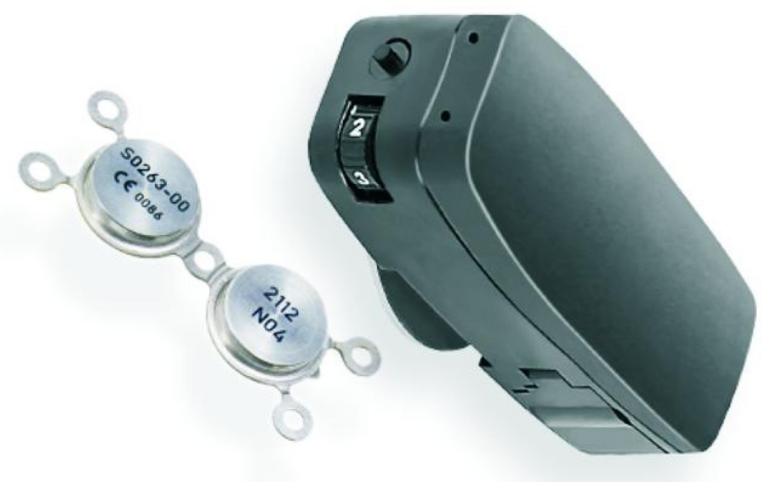

Figure 3 Sophono ${ }^{\circledR}$, a passive transcutaneous skin-drive bone-conduction device. Note: Image provided courtesy of Sophono ${ }^{\circledR}$. 
There are some generic issues from the conventional skindrive $\mathrm{BCD}$ related to the skin. First, since the vibrations pass through the skin, the static pressure must be high enough to provide the best transmission possible. A typical pressure is at least $2 \mathrm{~N},{ }^{3}$ which most often gives discomfort and problems in the skin and subcutaneous tissues between the transducer and the bone if used long-term. The high static pressure can also give tension headaches. Another drawback of transmitting the vibrations through the soft skin to the bone is that the vibrations get attenuated. This mainly affects the sound at frequencies above $1 \mathrm{kHz}$, which are important for speech reception. A third issue relates to feedback, where sound is radiated from the transducer back to the microphone. In early versions of the conventional skin-drive $\mathrm{BCD}$, the microphone was placed on the other side of the head from the transducer in order to reduce the feedback, but it can also be placed in a separate casing on the same side of the head, as is shown in Figure 2.

\section{Passive transcutaneous skin-drive BCDs}

Passive transcutaneous skin-drive BCDs have appeared on the market during the last few years and are available by Sophono ${ }^{\circledR}$ (Boulder, CO, USA [originally Otomag, Melle, Germany]) and Baha ${ }^{\circledR}$ Attract (Cochlear Bone Anchored Solutions AB).

\section{Sophono ${ }^{\circledR}$ device}

The Sophono ${ }^{\circledR}$ device was first presented by Siegert ${ }^{25}$ under the name Otomag system. It uses a retention magnet system where two magnets are implanted in the temporal bone, and fixated by five small titanium screws, and the sound processor is attached on the outside of the skin by magnetic attraction force (see Figure 3). The vibrations of the transducer are transmitted through the soft tissues, and the skin is most often thinned to $4-5 \mathrm{~mm}$ thickness (only in adults). ${ }^{26,27}$ In order to overcome skin problems related to high skin pressure, the Sophono ${ }^{\circledR}$ Alpha 1 uses a larger contact area than is used in conventional BCDs. In this way, the static force is distributed over a larger area, which alleviates the skin compression that might lead to circulatory problems. The company states that this larger area is also "impedance matched" in order to enhance the vibration transmission to the cochlea, but so far, no scientific papers are available verifying this effect.

In what follows, several clinical studies are presented, highlighting the most important results. A summary of audiometric results from studies, which are comparable in terms of how they have been measured, are found in Table 1.

Siegert and Kanderske ${ }^{27}$ made a retrospective study by inviting patients who had congenital atresia and who had been previously operated on (more than 100 patients since 2006). Twenty patients showed up, and it was found that they improved over the unaided condition by $28.6 \mathrm{~dB}$ in pure-tone average (PTA) and 61.6\% in speech-recognition score (SRS). No complications were reported from surgery, but some patients reported that they had slight pressure irritation of the skin between the implants and the external base plate which healed after careful shimming and slight force reduction of the base plates. ${ }^{27}$

Table I Summary of audiometric data of implantable bone conduction devices in clinical studies, only including studies that are reasonably comparable

\begin{tabular}{|c|c|c|c|c|c|c|c|c|c|}
\hline \multirow[t]{2}{*}{ Model } & \multirow[t]{2}{*}{ Type } & \multirow[t]{2}{*}{$\begin{array}{l}\text { No of } \\
\text { subjects }\end{array}$} & \multirow[t]{2}{*}{$\begin{array}{l}\text { PTAbc } \\
\text { [dB HL] }\end{array}$} & \multirow[t]{2}{*}{$\begin{array}{l}\text { Ages } \\
\text { [years] }\end{array}$} & \multirow[t]{2}{*}{ Etiology } & \multicolumn{3}{|c|}{$\begin{array}{l}\text { Aided vs unaided sound } \\
\text { field improvement }\end{array}$} & \multirow[t]{2}{*}{ Reference } \\
\hline & & & & & & $\begin{array}{l}\text { PTA }_{4} \\
\text { [dB HL] }\end{array}$ & $\begin{array}{l}\text { SRT } \\
\text { [dB HL] }\end{array}$ & $\begin{array}{l}\text { SRS } \\
{[\%]}\end{array}$ & \\
\hline \multirow[t]{4}{*}{ Bonebridge } & Active trans & 12 & $5-35$ & $19-69$ & Cond, mixed & 25 & $N / A$ & 78,8 & Sprinzl et al $^{59}$ \\
\hline & & 4 & $24-36$ & $45-63$ & Cond, mixed & 36,5 & 36,25 & N/A & Barbara et $a^{60}$ \\
\hline & & 6 & Average 26 & $40-57$ & Cond, mixed & $34,9 *$ & $\mathrm{~N} / \mathrm{A}$ & $80,0^{*}$ & Ihler et $\mathrm{al}^{62}$ \\
\hline & & 23 & $5-60$ & $6-80$ & Cond, mixed, SSD & $29 \ddagger$ & $N / A$ & 49 & Riss et $\mathrm{al}^{63}$ \\
\hline $\mathrm{BCl}$ & Active trans & 6 & $0-30$ & $18-67$ & Cond, mixed & 31,0 & 27,0 & $51,2^{+}$ & Reinfeldt et $\mathrm{al}^{50}$ \\
\hline \multirow[t]{3}{*}{ Sophono } & $\begin{array}{l}\text { Passive } \\
\text { trans }\end{array}$ & 20 of $>100$ & Average II & $6-50$ & Cond & 28,6 & N/A & 61,6 & $\begin{array}{l}\text { Siegert and } \\
\text { Kanderske }^{27}\end{array}$ \\
\hline & & 6 & $0-11$ & $5-11$ & Cond & $22 *$ & $28 *$ & $61^{*}$ & $\mathrm{Hol}$ et $\mathrm{al}^{28}$ \\
\hline & & 10 & $18-36$ & $16-67$ & Cond, mixed & $29,7^{*}$ & $34,1 *$ & $84, I^{*}$ & Magliulo et $\mathrm{al}^{31}$ \\
\hline Baha Attract & Passive trans & 9 of 12 & $3-26$ & $5-65$ & Cond & 19 & 19 & $\mathrm{~N} / \mathrm{A}$ & $\mid$ șeri et $\mathrm{al}^{33}$ \\
\hline BAHA HC 200 & Per & $110-122$ & $-1-45$ & Average 54 & Cond, mixed & 29,4 & 26,5 & $41,6^{+}$ & $\begin{array}{l}\text { Tjellström and } \\
\text { Håkansson }^{35}\end{array}$ \\
\hline
\end{tabular}

Notes: *Unaided measured with headphones; †SRS was measured with competing noise, signal-to-noise ratio =4 dB; $\neq$ average of 0.5 , I, 2, 3, 4, and $6 \mathrm{kHz}$.

Abbreviations: BAHA, bone-anchored hearing aid; BCl, bone-conduction implant; cond, conductive; HL, hearing level; N/A, not applicable; per, percutaneous; PTA , fourfrequency averages of pure-tone audiometry; PTAbc, pure-tone average for bone-conduction; SRS, speech-recognition score; SRT, speech-recognition thresholds; SSD, singlesided deafness; trans, transcutaneous. 
The Sophono ${ }^{\circledR}$ has been used on both children and adults, and in a comparative study between the Sophono ${ }^{\circledR}$ Alpha 1 and the percutaneous BAHA (six children with each device) by $\mathrm{Hol}$ et $\mathrm{al}^{28}$ the conclusion was that the BAHA-based outcome was slightly better in sound-field tone thresholds, speech-recognition thresholds (SRT) and SRS at $65 \mathrm{~dB}$ SPL (sound pressure level) without noise. Hol et $\mathrm{al}^{28}$ also stated that the Sophono ${ }^{\circledR}$ offers appealing clinical benefits with no adverse skin reactions or implant losses. In the subgroup of six children using the Sophono ${ }^{\circledR}$ Alpha 1, the improvement over the unaided condition was $22 \mathrm{~dB}$ in four-frequency PTA $\left(\right.$ PTA $_{4}$ ) (average over $0.5,1,2$, and $4 \mathrm{kHz}$ ); $28 \mathrm{~dB}$ in SRT, and $61 \%$ in SRS when no noise was added. It should be noted that the unaided condition here was measured with headphones and not in a sound field, which might affect the comparison, as measurements in a sound field might improve the unaided thresholds. For example, consider the situation where the patients have large air-bone gaps (ABGs) (range of 40-60 dB and below), then the free-field sound may pass through the skin and skull, as so-called "body conduction" that can be heard at lower levels than via AC through the ear canal. ${ }^{29}$

Sylvester et $\mathrm{al}^{30}$ investigated Sophono ${ }^{\circledR}$ Alpha 1 in 18 patients with different types of hearing impairments. They found that the best improvements were obtained for patients with bilateral conductive hearing loss, with an average functional gain of $21.9 \pm 10.4 \mathrm{~dB}$, but only minor improvement for bilateral mixed loss, with an average gain of $6.2 \pm 5.3 \mathrm{~dB} .{ }^{30}$

Magliulo et $\mathrm{al}^{31}$ showed that for their ten Sophono ${ }^{\circledR}$ patients with subtotal petrosectomy, the average difference between aided sound-field PTA and preoperative AC PTA was $29.7 \mathrm{~dB}$. They also got significant improvement in SRT of $34.1 \mathrm{~dB}$ and in SRS in quiet by $84.1 \%$ when comparing preoperative unaided values with headphones with aided sound-field values, where the contralateral ear was plugged and covered with an ear muff. ${ }^{31}$

A recent paper by $\mathrm{O}^{\prime} \mathrm{Niel}$ et $\mathrm{al}^{32}$ reported similar audiometric results for the Sophono ${ }^{\circledR}$ device as in the other studies but using a slightly different protocol, where in unaided condition the contralateral ear was masked and in the aided sound-field condition the contralateral ear was occluded. This different procedure for the contralateral ear might have affected the results. In this study, they stated that 5 out of 14 ears $(36 \%)$ had problems following fitting "including swelling, irritation, infection, or significant decreased ability to use the device from pain or skin changes." They have some recommendations to overcome these skin problems: decreased magnet strength at the initial fitting, a graduated wearing schedule, caution with patients who have a history of skin issues from a BAHA or multiple surgical procedures, and parent counseling regarding potential skin irritation in children. ${ }^{32}$

It seems that most of the other studies have noted skin problems in some of the patients and have managed them successfully in a similar way.

\section{Baha ${ }^{\circledR}$ Attract device}

Baha ${ }^{\circledR}$ Attract got the CE mark and was cleared by the Food and Drug Administration at end of 2013, and has since then been available on the EU and US markets. The magnet on the inside of the intact skin is attached to the skull bone with a screw, and the Baha ${ }^{\circledR}$ sound processor is attached to a magnet plate on the skin via a soft pad to equalize the force distribution over the attachment surface (see Figure 4). A multicenter clinical study, based on 27 patients, is completed and a publication is expected in the near future (noted from Cochlear Media Release, and the results were orally presented in the 29th Politzer meeting in Antalya, Turkey, 2013). The first available publication is not from this initial study, but instead

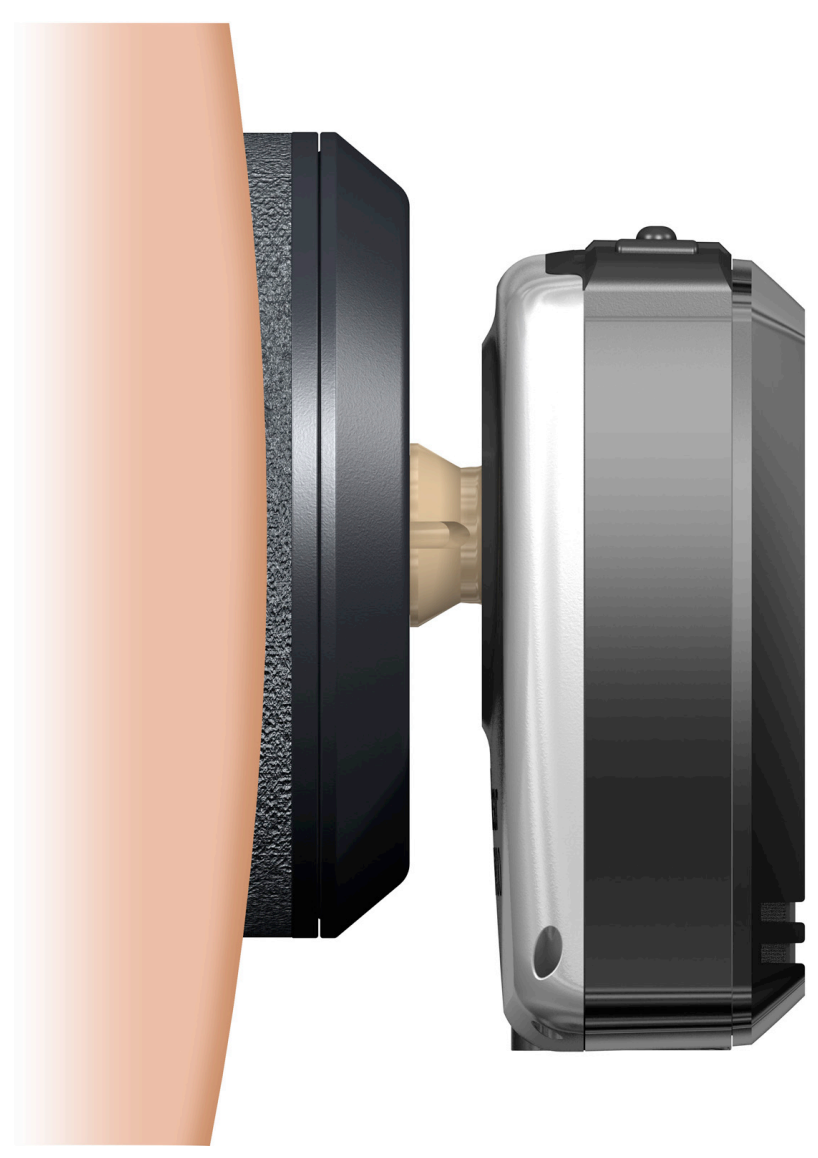

Figure 4 Baha ${ }^{\circledR}$ Attract, a passive transcutaneous skin-drive bone-conduction device. Note: Image provided courtesy of Cochlear Bone Anchored Solutions AB. 
describes the first experience in Turkey on 12 Baha $^{\circledR}$ Attract patients. ${ }^{33}$ They reported that bone smoothing (five patients) and soft-tissue reduction (four patients) was needed in some of the patients. No postoperative complications were reported, except that one patient had skin erythema which was solved by decreasing the magnet strength. In the audiometric investigation based on nine of the patients, they found an improvement in free-field PTA 4 of $19 \mathrm{~dB}$ and in free-field SRT of $19 \mathrm{~dB} \cdot{ }^{33}$ Another recently published study by Kurz et $\mathrm{al}^{34}$ investigated the speech understanding of the Baha ${ }^{\circledR}$ Attract by adding artificial skin and the external parts of the Baha ${ }^{\circledR}$ Attract system to a magnet on the abutment of 16 BAHA users. The contralateral ear was plugged and covered with an ear-muff for all sound-field measurements. They found that the transmission path through the artificial skin as expected gave a lower sensitivity, measured by "BC Direct" (which is a built-in feature of the sound processor that measures the electrical voltage directly fed to the transducer) for frequencies from $1 \mathrm{kHz}$ and above. However, only smaller differences in aided speech understanding between the transmission paths were found, which indicates that this lower sensitivity through the skin could at least partly be compensated for by adequate fitting (higher gain) in the speech processor. ${ }^{34}$

\section{Direct-drive BCDs}

In direct-drive BCDs, the vibrations are transmitted directly to the bone via a screw or a flat surface attachment. The direct-drive BCDs are mainly divided into percutaneous and active transcutaneous devices. It has been debated whether the implantable devices are active or passive. This classification has been based on definitions in regulatory directives in the EU and in the USA rather than on engineering principles. Thus, a BAHA is regarded as a passive device (Class IIb in EU), whereas a device with implanted transducer is regarded as an active device (AIMD in the EU and Class III in USA).

\section{Percutaneous direct-drive BCD}

The BAHA was the first available direct-drive BCD. It was developed to mitigate the drawbacks with the conventional device (ie, to improve rehabilitation in terms of better highfrequency sound transmission, and to avoid skin compression issues). In the BAHA, the sound processor is attached to the skull bone via an abutment to a titanium screw (see Figure 5). Hence, in the BAHA, the bone is directly stimulated without transmitting the vibrations through the skin.

There are two companies that manufacture BAHAs: Cochlear Bone Anchored Solutions AB and Oticon Medical. There have been major improvements of BAHA audio processors over the years. Cochlear Bone Anchored Solutions's most recent models are Baha ${ }^{\circledR} 3$ Power and Baha ${ }^{\circledR} 4$. Oticon Medical's most recent models are in the new Ponto Plus family. The models have different inclusion criteria regarding the sensorineural hearing component, and have been investigated in several studies. BAHAs are mainly indicated for conductive and mixed hearing loss as well as for single-sided deafness (SSD), and are used both on adults and on children.

Among the first results for percutaneous BAHA, Tjellström and Håkansson ${ }^{35}$ included approximately 120 patients with the HC 200 device. The improvements with the HC 200 over unaided condition was PTA $_{4}=29.4 \mathrm{~dB}$, SRT $=26.5 \mathrm{~dB}$, and $\mathrm{SRS}=41.6 \%{ }^{35}$ There are many recent studies with newer BAHA models, which have higher output capability, improved transducer technology, and better fitting procedure, but this original study follows essentially the same protocol as the studies presented here regarding other implantable BCDs, which facilitates comparison. By adopting more advanced signal
A

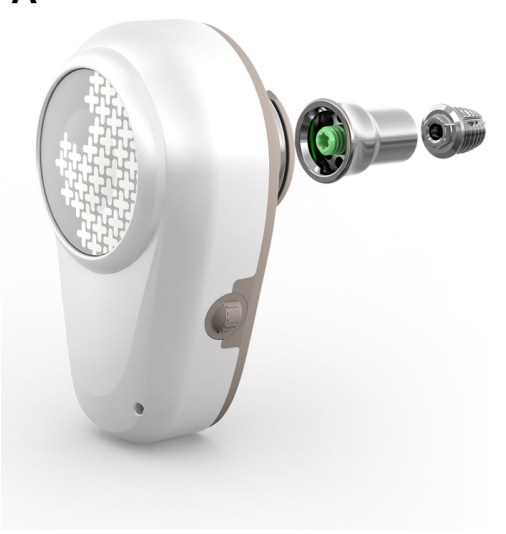

B

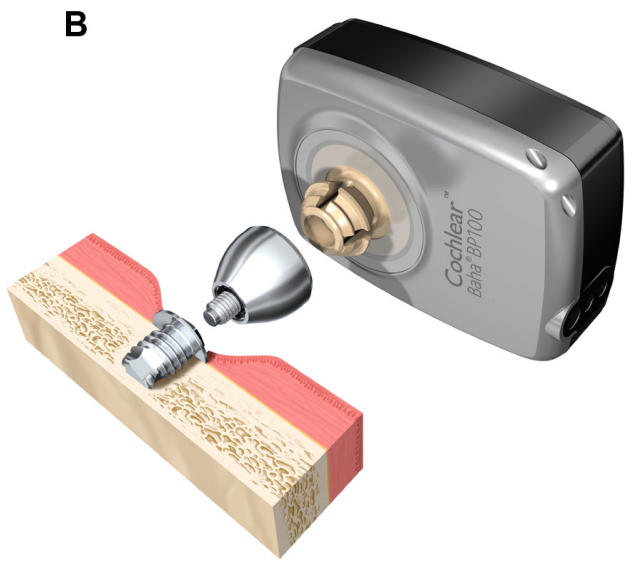

Figure 5 Bone-anchored hearing aid, a percutaneous direct-drive bone-conduction device.

Notes: (A) Ponto (Oticon Medical, Askim, Sweden); and (B) Baha ${ }^{\circledR}$ BPI 00 (Cochlear Bone Anchored Solutions AB, Mölnlycke, Sweden). Images provided courtesy of Oticon Medical (A) and Cochlear Bone Anchored Solutions AB (B). 
Table 2 MPO and reference thresholds for implantable BCDs

\begin{tabular}{|c|c|c|c|c|c|c|}
\hline \multirow[t]{2}{*}{ Device } & \multicolumn{5}{|c|}{ MPO in force level $[\mathrm{dB}$ re $I \mu \mathrm{N}]$} & \multirow[t]{2}{*}{ Comment/reference } \\
\hline & $0.5 \mathrm{k}$ & I k & $2 \mathrm{k}$ & $4 \mathrm{k}$ & PTA $_{4}$ & \\
\hline I. Bonebridge MPO @ Skullsimulator & 93 & 104 & $102^{*}$ & 84 & 95.8 & $\begin{array}{l}\text { Håkansson B, personal } \\
\text { communication, } 2014\end{array}$ \\
\hline 2. BCI MPO @ Skullsimulator & 97 & 102 & $94^{*}$ & 95 & 97.0 & $\begin{array}{l}\text { Taghavi et al, } \\
\text { unpublished data, } 2014\end{array}$ \\
\hline 3. RETFL DBC @ pos A (BAHA) & 48 & 45.5 & 26 & 27.5 & 36.8 & $\begin{array}{l}\text { Carlsson and } \\
\text { Håkansson }\end{array}$ \\
\hline 4. Correction: Pos $A(B A H A)$ vs pos $B(B C l)[d B]$ & 3 & 9 & 10 & 8 & 7.5 & Reinfeldt et al ${ }^{50}$ \\
\hline 5. RETFL DBC @ pos B (BCl) & 45 & 36.5 & 16 & 19.5 & 29.3 & Calculated ( 3 minus 4 ) \\
\hline
\end{tabular}

Notes: Pos A refers to the approximate skull position for a BAHA, $55 \mathrm{~mm}$ behind and slightly above the ear-canal opening. Pos B is the skull position for the BCl, $10-15 \mathrm{~mm}$ behind the ear-canal opening. Correction (4) is the calculation of the sensitivity difference between stimulation of the BCl and the BAHA positions (pos B and pos $\mathrm{A}$, respectively). @, attached to. *Values were taken slightly below $2 \mathrm{kHz}$ to avoid interference with a resonance peak.

Abbreviations: BAHA, bone-anchored hearing aid; $\mathrm{BCl}$, bone-conduction implant; $\mathrm{BCD}$, bone-conduction device; $\mathrm{DBC}$, direct bone conduction; MPO, maximum power output; pos $A$, position $A$; pos $B$, position $B ; P_{4}$, four-frequency pure-tone average; re, relative to; RETFL, reference equivalent threshold force level.

processing into the BAHA devices, speech understanding when noise comes from the rear is improved. ${ }^{36-38}$

BAHA has been a huge success with more than 150,000 users $^{6,7}$ and offers good hearing rehabilitation and is probably the most powerful BCD device today. Despite impressive audiometric results, the BAHA has some shortcomings. The skin around the abutment needs life-long daily care, and skin complications, such as skin irritation, skin infections, and skin growing over the abutment, occur. $^{8-13}$ The screw might come loose, ${ }^{8,39}$ either spontaneously or as a result of trauma. Although not scientifically investigated, some patients also reject a BAHA because of esthetic reasons. There have been several developments during recent years regarding the screw implant surface and shape, ${ }^{40-42}$ and surgical technique ${ }^{43-46}$ that have improved the situation regarding some of the complications. However, the fact remains that the implant is still percutaneous.

\section{Active transcutaneous direct-drive BCD}

In active transcutaneous direct-drive BCDs, the transducer is implanted under intact skin. Hence, the vibrations are transmitted from the transducer directly to the skull bone. The reason for calling it transcutaneous is that the electromagnetic signal from the sound processor is transmitted through the skin, not the vibrations. The sound processor is attached to the skin by retention magnets in the implanted unit, and the sound signal is transmitted via an inductive link to the implanted transducer. See Figure 6 for the BCI and Figure 7 for the Bonebridge ${ }^{\mathrm{TM}}$ from MED-EL (Innsbruck, Austria).

The BCI and the Bonebridge ${ }^{\mathrm{TM}}$ use similar inductive links ${ }^{47}$ and retention magnet systems, and the main difference between these devices is the transducer, and the BCI uses the balanced electromagnetic separation transducer (BEST) principle ${ }^{48}$ with a high-frequency boost. By using the BEST principle, the BCI transducer is smaller and has lower distortion and higher efficiency compared with the transducer that is used in BAHAs. ${ }^{48}$ The BCI transducer casing has a rectangular shape with rounded corners, and the size is approximately $14 \mathrm{~mm} \times 12 \mathrm{~mm} \times 7.4 \mathrm{~mm}$. The Bonebridge ${ }^{\mathrm{TM}}$ uses a floating mass transducer that has a cylindrical shape with diameter $15.8 \mathrm{~mm}$ and height $8.7 \mathrm{~mm}$.

Table 3 Maximum dynamic ranges and suggested BC thresholds for implantable BC devices

\begin{tabular}{|c|c|c|c|c|c|c|c|}
\hline \multirow[t]{2}{*}{ Device } & \multicolumn{5}{|c|}{$\begin{array}{l}\text { Max dynamic range with normal } \\
\text { cochlear function [dB HL] }\end{array}$} & \multirow[t]{2}{*}{$\begin{array}{l}\text { Comment/ } \\
\text { reference }\end{array}$} & \multirow[t]{2}{*}{$\begin{array}{l}\text { Max PTAbc at aided } \\
\text { PTA }=30-35 \mathrm{~dB} \text { HL }\end{array}$} \\
\hline & $0.5 \mathrm{k}$ & I k & $2 \mathrm{k}$ & $4 \mathrm{k}$ & PTA $_{4}$ & & \\
\hline Bonebridge Alt I & 48 & 68 & 86 & 65 & 67 & Calculated* & $32-37$ \\
\hline Bonebridge Alt 2 & 55 & 61 & 71 & 60 & 62 & Mertens et $\mathrm{al}^{73}$ & $27-32$ \\
\hline $\mathrm{BCl}$ & 52 & 66 & 78 & 76 & 68 & Calculated** & $33-38$ \\
\hline Sophono @ Skullsimulator & 51 & 53 & 64 & 50 & 54 & Zwartenkot ${ }^{70}$ & $19-24$ \\
\hline Baha Divino@ @kullsimulator & 64 & 68 & 75 & 68 & 69 & Zwartenkot ${ }^{70}$ & $34-39$ \\
\hline Baha Cordelle@ @kullsimulator & 80 & 75 & 87 & 81 & 81 & Zwartenkot ${ }^{70}$ & $46-51$ \\
\hline
\end{tabular}

Notes: Dynamic range is calculated from Table 2 and from published MPO dB HL data. Indication range in PTA $\mathrm{BC}_{4}$, assuming aided PTA 4 of $30-35 \mathrm{~dB} H \mathrm{HL}$, is calculated as the dynamic range minus 30-35 dB. *Row I minus row 5 in Table 2; **row 2 minus row 5 in Table 2. @, attached to.

Abbreviations: Alt, alternative; $\mathrm{BC}$, bone-conduction; $\mathrm{BCl}$, bone-conduction implant; HL, hearing level; max, maximum; MPO, maximum power output; PTA, pure-tone average; PTA, four-frequency pure-tone average; PTAbc, pure-tone average for bone-conduction. 


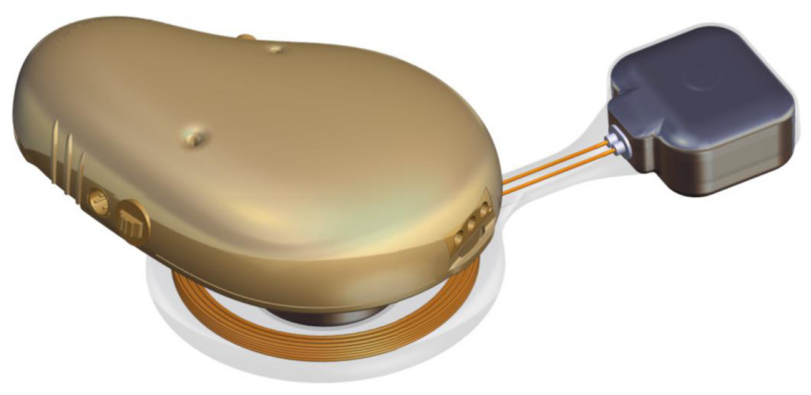

Figure 6 Bone-conduction implant, an active transcutaneous direct-drive boneconduction device.

The BCI system was developed in collaboration between Chalmers University of Technology and Sahlgrenska University Hospital in Gothenburg, Sweden. The clinical study on 20 patients is ongoing, and so far, six patients have received the implant. The audiometric results of the first patient at the 1-month follow-up are published by EegOlofsson et a $1^{49}$ and the first six patients' 6-month follow-up by Reinfeldt et al. ${ }^{50}$ Before the clinical study, preclinical studies were performed on cadavers, ${ }^{51-54}$ dry skulls,,${ }^{55}$ animals, ${ }^{56,57}$ and normal-hearing subjects. ${ }^{58}$ In the important preclinical studies on the cadavers, ${ }^{51,52}$ where it was first concluded that an active transcutaneous BCD could be a realistic alternative to a percutaneous system, the sound processor and induction link from the Vibrant Soundbridge (the study was supported by MED-EL) was used to drive a BEST transducer. One important finding in these investigations was that MPO in the transcutaneous solution was considered high enough compared with a percutaneous BAHA solution, which most likely triggered the work to develop complete active transcutaneous systems like the $\mathrm{BCI}$ and the Bonebridge ${ }^{\mathrm{TM}}$ systems.

Reinfeldt et $\mathrm{al}^{50}$ showed that the improvement from unaided to aided $\mathrm{PTA}_{4}$ for the first six patients using the $\mathrm{BCI}$ was $31.0 \pm 8.0 \mathrm{~dB}$. The SRT improvement was $27.0 \pm 7.6 \mathrm{~dB}$,

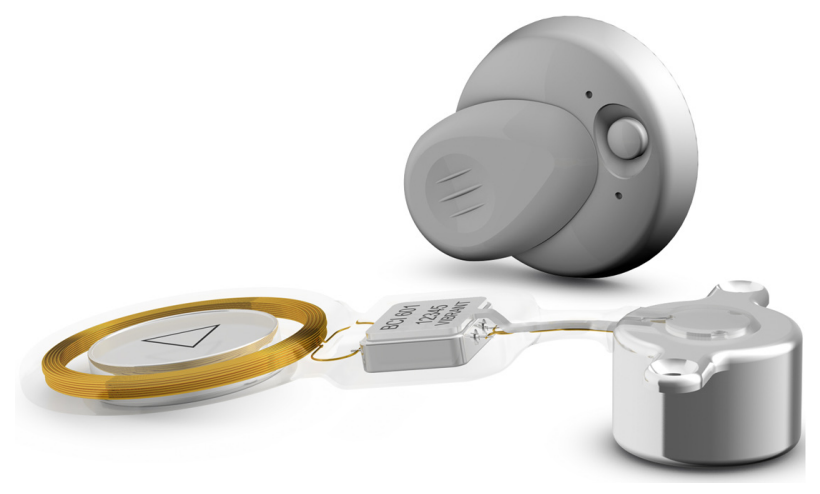

Figure 7 Bonebridge $^{\mathrm{TM}}$, an active transcutaneous direct-drive bone-conduction device.

Note: Image provided courtesy of MED-EL. the SRS improvement was $51.2 \% \pm 8.9 \%$, while the signal-tonoise ratio threshold for the $\mathrm{BCI}$ was $-5.5 \pm 2.3 \mathrm{~dB}$. Also, the questionnaires APHAB (Abbreviated Profile of Hearing Aid Benefit) and GBI (Glasgow Benefit Inventory) showed significant improvement in quality of life for the patients using the BCI. Furthermore, it was found that the BCI results were better or similar compared with the results of a BAHA (Ponto Pro Power) on a softband, which was used for 1 month prior to the BCI surgery. It was concluded in the study that the $\mathrm{BCI}$ gives significant hearing rehabilitation for patients with mild-to-moderate conductive or mixed hearing loss, and that the surgical procedure is safe and uncomplicated. ${ }^{50}$

The Bonebridge ${ }^{\mathrm{TM}}$ was developed by MED-EL and has been on the market since spring 2012, indicated for patients with conductive and mixed hearing loss, and SSD. Since 2014, it has also been approved for children from 5 years of age. Sprinzl et al ${ }^{59}$ operated on 12 adult patients with Bonebridge ${ }^{\mathrm{TM}}$, and after 3 months, the average improvement in sound-field $\mathrm{PTA}_{4}$ was approximately $25 \mathrm{~dB}$. The corresponding improvement in SRT was on average $25.3 \mathrm{~dB}$, and in SRS in quiet, $78.8 \% .{ }^{59}$ Four patients with Bonebridge ${ }^{\mathrm{TM}}$ presented by Barbara et a ${ }^{60}$ showed an average improvement in $\mathrm{PTA}_{4}$ of 36.5 $\mathrm{dB}$ and in SRT of $36.25 \mathrm{~dB}$. Manrique et $\mathrm{al}^{61}$ and Ihler et $\mathrm{al}^{62}$ calculated the improvement as the difference between preoperative unaided PTA-AC (with headphones) and aided PTA in sound field. Manrique et $\mathrm{al}^{61}$ had four Bonebridge ${ }^{\mathrm{TM}}$ patients with conductive or mixed hearing loss and presented a threshold PTA 4 improvement of $36.9 \pm 8.5 \mathrm{~dB}$, and Ihler et $\mathrm{al}^{62}$ had six patients with an average $\mathrm{PTA}_{4}$ improvement of $34.9 \pm 4.5 \mathrm{~dB}$. Manrique et $\mathrm{al}^{61}$ also had one SSD patient who presented separately where the improvement in $\mathrm{PTA}_{4}$ was $17.5 \mathrm{~dB}$. In a recent study by Riss et al, ${ }^{63} 23$ patients with Bonebridge ${ }^{\mathrm{TM}}$ were evaluated, showing an overall average improvement of $28.8 \pm 16.1 \mathrm{~dB}$ for $0.5-6.0 \mathrm{kHz}$, using sound field in both aided and unaided measurements. The contralateral ear was covered with an ear-muff. By comparing preoperative $\mathrm{BC}$ thresholds with the benefit of the implant, they concluded that it is advisable that the preoperative thresholds at all frequencies are better than $45 \mathrm{~dB}$ HL (hearing level), as stated by the company in the Indications for Use. ${ }^{63}$ Finally, in a study by Plontke et $\mathrm{a}^{64}$ on six subjects, a three-dimensional planning tool to prepare for the surgery was presented. Given the size of the implant, the Bonebridge ${ }^{\mathrm{TM}}$ surgery is deemed to be rather difficult, especially if the transducer is to be fitted within the mastoid boundaries. The audiometric results in Plontke et a ${ }^{64}$ are similar to those in the other studies.

Several of the papers stress that the big size of the Bonebridge $^{\mathrm{TM}}$ implant can be a challenge, especially in 
patients with a mastoid open cavity and in children who have smaller temporal bones. In most studies, it is stated that careful preoperative investigations using computed tomography (CT) are needed in order to find a possible site for implantation. This site could be retrosigmoidal if not enough space is found in the mastoid. A consequence is often that the dura is exposed and possibly pushed down to fit the implant. As an example, Lassaletta et $\mathrm{a}^{65}$ reports a case of one patient where a retrosigmoid position was the only option. For a complete insertion, a gentle compression of the dura was needed. MED-EL has recently released a Lifter system by which the whole implant is moved outwards from the skull bone, thus lifting the skin in that area in order for the implant to fit the mastoid cavity.

\section{In-the-mouth BCD}

A category of BCDs that is neither regarded as direct-drive nor skin-drive, is the in-the-mouth device. The vibrations are generated by a piezoelectric transducer and are transmitted through the teeth to the skull bone. SoundBite ${ }^{\mathrm{TM}}$ by Sonitus Medical (San Mateo, CA, USA) was developed mainly for SSD patients. A microphone is placed behind the ear on the deaf side, and the sound is sent wirelessly to an in-the-mouth transducer, transmitting vibrations to the upper back teeth. These vibrations are transmitted to the skull bone and received by the healthy cochlea. In this way, the healthy cochlea hears the sound from both sides. The SoundBite ${ }^{\mathrm{TM}}$ is illustrated in Figure 8.

Evaluations by Murray et a ${ }^{66,67}$ showed that the SoundBite ${ }^{\mathrm{TM}}$ system is safe and effective, with a substantial benefit for SSD patients with continual daily use. Gurgel and Shelton ${ }^{68}$ have shown significant APHAB score improvements of, on average, 21 points.

The most commonly reported problem with the SoundBite ${ }^{\mathrm{TM}}$ is acoustic feedback. ${ }^{68}$ Feedback can be minimized with proper fitting but still remains for some patients. Another challenge

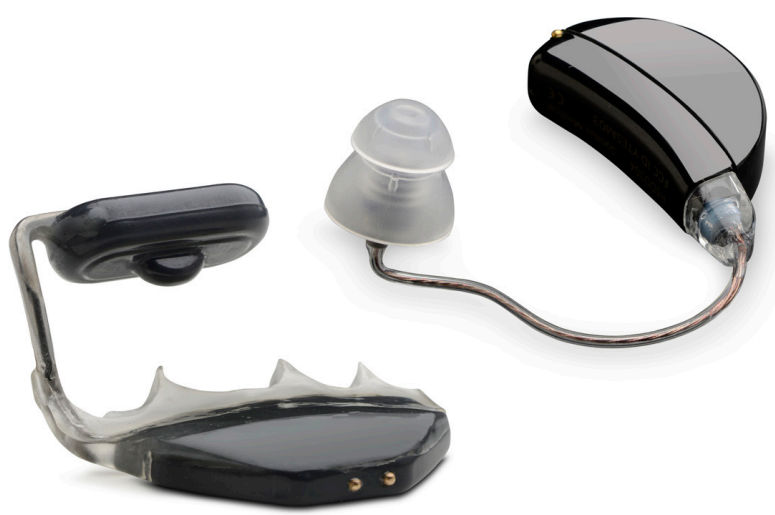

Figure 8 SoundBite ${ }^{\mathrm{TM}}$, an in-the-mouth bone-conduction device with implant for tooth attachment and behind-the-ear sound processor.

Note: Image provided courtesy of Sonitus Medical. with this type of device is that it provides less output at lower frequencies due to size and power issues. Syms and Hernandez ${ }^{69}$ give an overview of maximum power output in eight BCDs, which showed that the SoundBite ${ }^{\mathrm{TM}}$ has its highest output and gain in the frequency range above $2 \mathrm{kHz}$. SSD patients mainly need high-frequency gain to overcome the head shadow effect; hence, for these patients, the SoundBite ${ }^{\mathrm{TM}}$ can be a good alternative. There might also be distortion and discomfort issues when eating. This aspect should not be overlooked, since conversation during meals is a daily situation where good hearing ability is of great importance.

\section{Maximum power output and bone- conduction threshold indication}

Suggested indication ranges concerning $\mathrm{BC}$ thresholds for some implantable BCDs, according to companies' recommendations, are not always supported by published clinical data. Therefore, one purpose of this review is to summarize audiometric results and try to relate them to a range of recommended bone-conduction thresholds for use.

In this early phase of implantable BCDs lacking enough clinical data, one alternative way is to use the objectively measured MPO of these devices, and normalhearing threshold data, in order to calculate a guidance to an indication range. Zwartenkot et $\mathrm{al}^{70}$ argued that the aided PTA should be at least $35 \mathrm{~dB}$ HL to get a word recognition score of $75 \%$, as proposed by Mueller and Killion ${ }^{71}$ for $\mathrm{AC}$ hearing. A summary of such calculations is presented in Table 2 and 3, with an estimated indication range based on the fact that the aided PTA 4 should be 30-35 dB HL. The authors of this review believe that requiring $35 \mathrm{~dB} \mathrm{HL}$ as aided $\mathrm{PTA}_{4}$ is slightly too conservative and that $30 \mathrm{~dB} \mathrm{HL}$ may be sufficient for BCDs, due to 1) that hearing by $\mathrm{BC}$ may have a steeper loudness growth than $\mathrm{AC} ;{ }^{72}$ and 2) patients with severe conduction hearing loss may accept some limitation of peak levels in their own voice, given that other alternatives may have even more severe drawbacks. Therefore it might be advisable to have a grey zone of $5 \mathrm{~dB}$ (ie, the aided PTA should be (at least) in the range of 30-35 dB HL). Assuming that the aided $\mathrm{PTA}_{4}$ should be at least $30 \mathrm{~dB} \mathrm{HL}$, then the maximum recommended inclusion level preoperatively in PTA for bone conduction (PTAbc) $(0.5,1,2$, and $4 \mathrm{kHz})$ should be 32-37 dB HL for the Bonebridge ${ }^{\mathrm{TM}}, 38 \mathrm{~dB}$ HL for the BCI, $24 \mathrm{~dB}$ HL for the Sophono ${ }^{\circledR}, 39 \mathrm{~dB}$ HL for the Baha Divino, and $51 \mathrm{~dB}$ HL for the Baha Cordelle.

The reason for having two values of maximum PTAbc for Bonebridge ${ }^{\mathrm{TM}}$ is related to there being two alternative methods for the MPO estimation used. One method (Alt 1) 
is based on skull simulator measurements and reference equivalent force threshold levels, same as for BCI, and the other method (Alt 2) is experimental and is taken from Mertens et $\mathrm{al}^{73}$ (made in situ on patients). Apparently, the average dynamic range according to Alt 1 is $5 \mathrm{~dB}$ higher than the dynamic range according to Alt 2 . One reason may be that the correction for increased sensitivity in Position $\mathrm{B}$ relative to Position $\mathrm{A}$ is less for Bonebridge ${ }^{\mathrm{TM}}$, as it has a more rigid bone attachment by using two separated bone screws anchored in the outer bone surface. Moreover, one can assume that the stronger ear level devices available today from Oticon Medical (Ponto Plus Power) and Cochlear Bone Anchored Solutions (BP 110 power) should have maximum indication range in between those values calculated for Divino and Cordelle. Finally, the maximum preoperative BC thresholds are indicative and should only be used as guidance, given that all other inclusion criteria are met. The suggested preoperative $\mathrm{BC}$ threshold levels for inclusion are also presented in Figure 9.

A summary of the studies discussed in this review is displayed in Table 1. Only results that are reasonably comparable have been included.

\section{Differences between study protocols}

One important note that might affect these comparative results is related to how the unaided condition was measured. The method of using headphones in the unaided condition may, as has been described in the Sophono device section, result in a larger gain compared to if sound field measurements are used. The authors believe that the unaided condition should be measured in sound field in the same way as the aided condition.

Another issue is how the contralateral ear should be managed. The authors' opinion is that it should be blocked by a deep inserted ear-plug to avoid the occlusion effect. ${ }^{74}$ Bone-conducted sound will cross over to the contralateral cochlea, which is why masking of the contralateral cochlea is a non-physiological way of comparing aided and unaided condition. Like in all BC applications, the cochlea that is dominant (ipsilateral or contralateral) may vary over frequency. Additionally, if masking is used, there is a risk of central masking, and also over masking, in cases with large ABGs.

Yet another difference is how the speech perception result will be affected if including a competing noise or not in the setup. For the patient, the most common and demanding situation is to perceive speech in a noisy environment. To only include speech in quiet does not give any information about how the hearing aid functions in the important noisy situation for the user.

\section{Caution using $A B G$ when evaluating effectiveness of BCDs}

There is a tradition among ENT (ear, nose, and throat) specialists to discuss whether a device (or surgical treatment) is closing the $\mathrm{ABG}$ or not. If a BCD closes the $\mathrm{ABG}$, it is generally regarded as an effective device in hearing rehabilitation.

The ABG is defined as the difference between $\mathrm{AC}$ thresholds, measured by headphones, and BC thresholds, measured

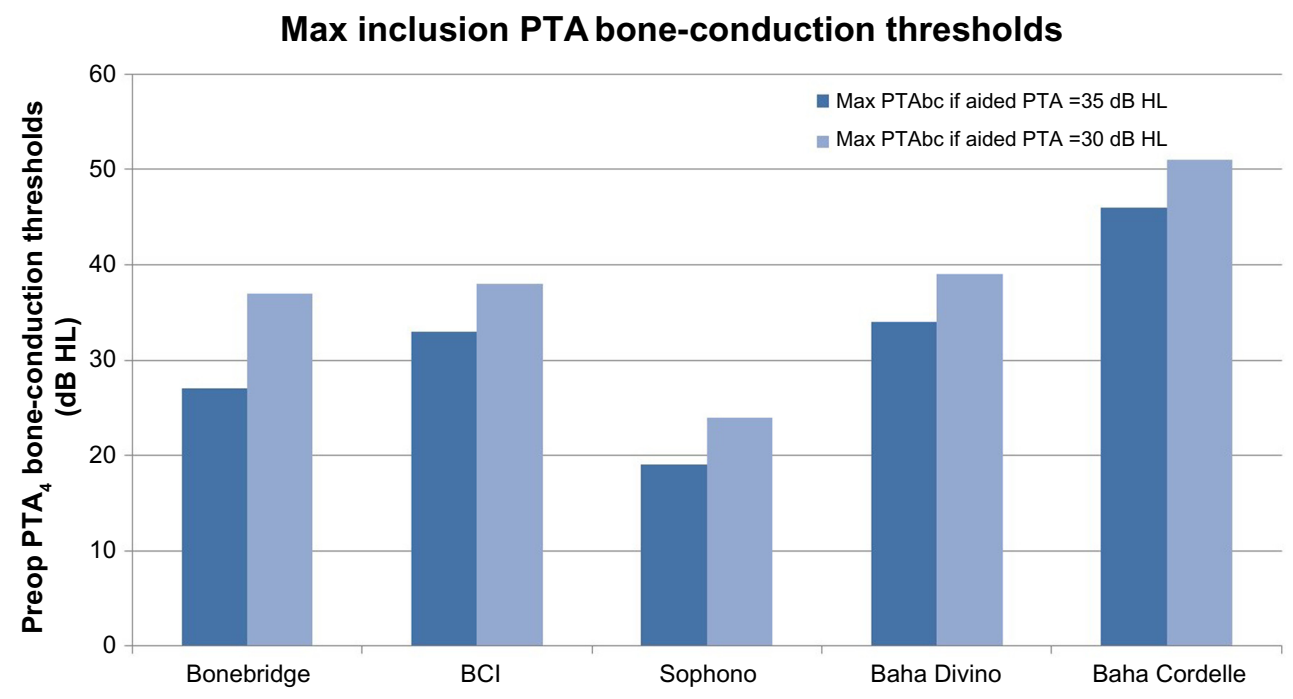

Figure 9 Estimated maximum recommended preoperative bone-conduction thresholds, which include a "gray" zone depending on if an aided PTA of at least 30 or $35 \mathrm{~dB}$ $\mathrm{HL}$ is met.

Abbreviations: $\mathrm{BCl}$, bone-conduction implant; $\mathrm{HL}$, hearing level; max, maximum; preop, preoperative; PTA, pure-tone average; PTA, four-frequency averages of PTA; PTAbc, pure-tone average for bone-conduction. 
by bone conductor B71/B81 for one specific ear (left or right). By including the aided sound-field thresholds in the same audiogram, some argue that the effectiveness of the device can be evaluated. For example, if the aided thresholds coincide with the bone thresholds, the ABG is closed by the device (ie, one could say that the device has fully compensated the conductive loss). However, the authors of this review would like to argue that one must be aware that both cochleae are stimulated in the aided condition, whereas the audiogram presents the hearing ability of an individual ear, and it is impossible to know with which cochlea the patient is hearing in the aided condition unless the treated cochlea is much better than the contralateral cochlea. Depending on position, frequency, and individual BC physiology, the two cochleae are stimulated with different amplitudes. Based on this understanding, the modern BAHAs today, both from Cochlear Bone Anchored Solutions and Oticon Medical, use a built-in function generator to measure the total $\mathrm{BC}$ sensitivity ("BC Direct") when attached to the implant in the fitting procedure. This is logical, as the device in the aided condition uses the total sensitivity from both cochleae and must be fitted to this situation for each given frequency. Therefore, the closure or non-closure of the ABG, as defined above, should be considered with caution when discussing hearing rehabilitation for patients using a BCD. Furthermore, a successful hearing rehabilitation depends on many factors, and the closure or non-closure of the ABG should in this sense be regarded as of minor importance.

\section{Trends in developing BCDs}

General trends in hearing devices are to either make them more esthetically appealing or to make them as invisible as possible. By changing the sound transmission from percutaneous to transcutaneous, the visibility of wearing a hearing aid reduces. However, the main reason for developing transcutaneous devices is the complications associated with skin penetration. These complications have been reduced by improvement in the screw and abutment design, and by introducing less invasive surgical techniques, but they can only be completely eliminated by leaving the skin intact. In all the new devices presented in this review paper, the skin is intact, and the vibrations are transmitted through the skin (passive transcutaneous skin-drive BCDs), directly into the bone (active transcutaneous direct-drive BCDs) or via the teeth (in-the-mouth BCDs). Hence, the trend is definitely towards implantable devices with intact skin.

There are several challenges in developing implantable BCDs: 1) they must be powerful enough, 2) they must have a good and long-term stable attachment, 3) they must be effective and safe for the patient, and 4) they should have a solution that is safe for the patient, and preferably also safe for the $\mathrm{BCD}$, if a magnetic resonance imaging (MRI) investigation is needed.

The first challenge regarding sufficient power is important, and also evident from the failures of the Xomed Audiant, and to some extent also the conventional BCDs. The conventional $\mathrm{BCDs}$ are less powerful than the BAHA. The MPO limits the output force level of the device, and the patient must have sufficient headroom for ordinary speech levels to avoid distorted sound. A reduced MPO also limits the useful gain of the device. In active transcutaneous BCDs, the MPO is reduced about $10-15 \mathrm{~dB}$ by using an inductive link through the skin. ${ }^{47,75}$ This is a significant loss, and from the experience with BAHA, it can be concluded that such a loss should severely limit the use of a link driven device if that loss could not be compensated in some way. However, it has been shown that the sensitivity increases for $\mathrm{BC}$ stimulation positions closer to the cochlea. It was found that the acceleration, measured by laser Doppler vibrometry on the cochlear promontory of cadavers increased by $5-15 \mathrm{~dB}$ at frequencies between $600 \mathrm{~Hz}$ and $10 \mathrm{kHz}$ by moving the stimulation position closer to the cochlea ${ }^{51-53}$ as compared with the standard BAHA position $55 \mathrm{~mm}$ behind the bony ear canal. To compare this improved vibration sensitivity to hearing sensitivity (hearing thresholds) in patients, two studies were conducted, showing that the hearing not only increased in the range from $600 \mathrm{~Hz}$ to $10 \mathrm{kHz}$, but also increased at lower frequencies down to $125 \mathrm{~Hz} .58,76$ For the BCI, in which the transducer also has a high-frequency boost around $4.5 \mathrm{kHz}$, the inductive link loss is thus compensated for by moving the stimulation position closer to the cochlea, and by the high-frequency boost. ${ }^{58}$

A second challenge is how to attach and fit the implanted transducer casing to the skull bone. A possible solution would be to use a titanium screw in the drilled recess of the bone. This solution was tested in a cadaver study by Håkansson et $\mathrm{al}^{51}$ with good cochlear acceleration as result. However, the engagement of inserting screws into deeper areas of the temporal bone in humans is hazardous, with a high risk of damaging the facial nerve, semi-circular canals, and other delicate structures. The mastoid part of the temporal bone is built up by air cells, which would also have a negative effect of the stability of a screw attachment. In the Bonebridge ${ }^{\mathrm{TM}}$, the transducer is attached with two osseointegrated screws inserted at the surface of the skull bone, one at each side of the transducer casing, and thus anchored in the outer compact bone, which is safe and similar to what is used in the BAHA. 
The vibrations of the BC floating mass transducer are then transmitted to the bone via the screws, and therefore a small clearance between the transducer casing and the bone is created at the bottom of the drilled recess.

In all preclinical investigations, it has been shown that the highest sensitivity is achieved if the transducer is attached as close as possible to the cochlea. This is one of the reasons that the BCI transducer is attached against the flat surface in a prepared bottom plane of the recess. It has been proven in an animal study that the transmission to the bone is equally good with a flat surface attachment as if it had been attached with a screw, ${ }^{56}$ which is also seen by the bone contact underneath the transducer ${ }^{57}$ (ie, the implant was found to be osseointegrated). The transducer protrudes $1-2 \mathrm{~mm}$ from the bone surface and is secured with a titanium wire over the casing, as described in Reinfeldt et al. ${ }^{50}$ It has been discussed whether it will be possible to just use compliant resorbable sutures instead. Even if the procedure is easy as it is done today, there might be future simplifications of this surgery. Yet another reason that a flat surface attachment was chosen for the BCI is that it is easier to install and also to remove the implant. The simplicity of removing the implant can be important if, for example, an MRI examination of the head is necessary, or in the case of transducer malfunction.

Size might also be an issue, and this was actually yet another reason to choose a flat surface contact in the bottom of the recess, because it allows an implant of maximum height in a limited given space. Not only the height, but also the width of the implant, is crucial if the BCI transducer should fit most temporal bones. Temporal bones are varying in size and might have reduced size, due to chronic infections, malformations, or a history of ear surgeries. By studying normal temporal bones, it was concluded that for an implant of $16 \mathrm{~mm}$ in diameter, the maximum depth into the temporal bone can be $4 \mathrm{~mm}$ to statistically fit $95 \%$ of all patients with normal temporal bones. ${ }^{77}$ If the implant diameter is $12 \mathrm{~mm}$, the maximum depth into the temporal bone can be $6 \mathrm{~mm}$. The BCI transducer size has been based on these results (size $14 \mathrm{~mm} \times 12 \mathrm{~mm} \times 7.4 \mathrm{~mm}$ ), and it fits with good margin in all patients included in the Reinfeldt et al ${ }^{77}$ study. From a statistical point of view, and taking the actual implant sizes and the allowance of protrusion from the bone surface into account, the BCI transducer fits in $95 \%$ and the Bonebridge ${ }^{\mathrm{TM}}$ transducer fits in $40 \%$ of normal temporal bones. ${ }^{77}$

The third challenge concerns the invasiveness of the surgery. Less invasive surgery usually implies less risk for the patient, and an easier and less costly surgical procedure. The deeper the engagement in the bone, the more complicated the surgery. This statement might be a reason why none of the middle-ear implants have reached the success that many believed they would in the 1990s. All surgeries for BCDs have been regarded as safe and simple in publications, although there could be different grades of the simplicity. The BAHA surgery can now be carried out in 10-15 minutes under a local anesthesia with the punch technique. ${ }^{45}$ The $\mathrm{BCI}$ and the Bonebridge ${ }^{\mathrm{TM}}$ surgeries are performed under a general anesthesia in most cases. In the Bonebridge ${ }^{\mathrm{TM}}$, there have been several reports that indicate that the surgery can be more difficult because of size issues. For example, in the presurgical evaluation, it must be decided whether it fits in the mastoid portion of the temporal bone, or whether a retrosigmoidal position has to be considered. A radiologic evaluation is therefore mandatory in this preparatory phase. In the BCI, only six patients have been operated on so far; however, in none of these has size been an issue, and it is suggested that a radiologic preparatory investigation is only needed if the patient has either malformations of the temporal bone, or have been exposed to previous ear surgeries resulting in an open mastoid cavity. Both the procedure for the Bonebridge ${ }^{\mathrm{TM}}$ and for the BCI can likely be considered to be performed under a local anesthesia in the future, if desired.

The fourth and final challenge concerns the MRI compatibility. A CT, or a low radiation cone beam CT should be used as a first choice, but some clinical conditions require MRI to obtain the relevant image information. As indicated above, the possibility to perform an MRI investigation is an important issue in all implantable BCDs as they contain permanent magnet(s) for retention, and in the active devices (Bonebridge ${ }^{\mathrm{TM}}$ and $\mathrm{BCI}$ ) there are also soft iron components and permanent magnets inside the transducer. Even if the implanted parts can be made conditionally MRI safe (Bonebridge ${ }^{\mathrm{TM}}$ and Sophono ${ }^{\circledR}$ Alpha 1 are certified to be conditionally safe up to 1.5 and 3 Tesla, respectively), there will be an image artifact in a region near the implant. If an MRI absolutely needs to be done with focus on structures in the skull near the implant, the implant must be explanted to eliminate artifacts due to the BCD. Therefore it is important to design the implant for such an event. In the BCI, prerequisites for an easy explantation has been accomplished by not using screws for the attachment. Instead, an osseointegrated flat surface is used, and the retention is made by an easily removable titanium wire over the implant anchored in the outer skull surface. Moreover, regarding the BCI, and after studying demagnetization and torque of different types of retention magnets, the BCI implant is considered to be MRI conditional at a static magnetic 
field of 1.5 Tesla and with a compression band around the skull to fixate the implant. ${ }^{78}$ However, this is not yet approved and requires further verification. ${ }^{78}$

\section{Conclusion}

This paper is a review of existing BCDs on the market or in ongoing clinical trials for market approval. They are presented under the categories direct-drive, skin-drive, and in-the-mouth BCDs. The skin-drive devices are divided into conventional and passive transcutaneous devices, while the direct-drive devices are divided into percutaneous and active transcutaneous devices. Because of soft-tissue challenges with percutaneous implants, the trend in BCDs is towards transcutaneous semi-implantable devices, where the skin is kept intact. The four main challenges with transcutaneous solutions are related to sufficient power, firm and stable implant attachment, surgical invasiveness, and MRI compatibility. When comparing the hearing improvement with the different devices, the direct-drive BCDs, both percutaneous and active transcutaneous, provide the best hearing rehabilitation, mainly because of the direct stimulation of the bone (no vibrations through the skin).

In summary, the authors believe that the existing percutaneous direct-drive BCD (the BAHA) will be retained as an important part in hearing rehabilitation, due to excellent sound quality and high output power. In the future, intact skin solutions will probably replace part of the market from the BAHA, and it seems that the active transcutaneous direct-drive BCDs (Bonebridge ${ }^{\mathrm{TM}}$ and $\mathrm{BCI}$ ) are the most promising systems at present, but more extensive clinical studies are needed to specify detailed inclusion criteria, and potential benefits and drawbacks of these devices.

\section{Disclosure}

Bo Håkansson holds several patents related to the BCI device. The other authors report no conflicts of interest in this work.

\section{References}

1. Berger KW. Early bone conduction hearing aid devices. Arch Otolaryngol. 1976;102(5):315-318.

2. Mudry A, Tjellström A. Historical background of bone conduction hearing devices and bone conduction hearing aids. Adv Otorhinolaryngol. 2011;71:1-9.

3. von Békésy G. Experiments in Hearing. New York: McGraw-Hill; 1960.

4. Brånemark PI, Hansson BO, Adell R, et al. Osseointegrated implants in the treatment of the edentulous jaw. Experience from a 10-year period. Scand J Plast Reconstr Surg Suppl. 1977;16:1-132.
5. Håkansson B, Tjellström A, Rosenhall U, Carlsson P. The bone-anchored hearing aid: principle design and a psychoacoustical evaluation. Acta Otolaryngol. 1985;100:229-239.

6. News and research in bone conduction hearing - craniofacial osseointegration [press release]. Mölnlycke: Cochlear Bone Anchored Solutions AB; 2011 [June 11]. Available from: http://www.cochlear.com/wps/ wcm/connect/0a7aa3b7-8ad8-40ab-b288-20054c04e3e2/en-Baha-Osseo-Press-Release-2013-June-11.pdf?MOD=AJPERES\&CONVERT_ $\mathrm{TO}=$ url\&CACHEID $=0 \mathrm{a} 7 \mathrm{aa3b} 7-8 \mathrm{ad} 8-40 \mathrm{ab}-\mathrm{b} 288-20054 \mathrm{c} 04 \mathrm{e} 3 \mathrm{e} 2$. Accessed November 4, 2014.

7. Oticon Medical. Oticon Medical-taking ideas further.2014.Available from: http://www.oticonmedical.com/ asset/cache. ashx?id=7229\&type= 14\&format=web. Accessed September 16, 2014.

8. Dun CAJ, Faber HTF, de Wolf MJF, Mylanus EAM, Cremers CWRJ, Hol MKS. Assessment of more than 1,000 implanted percutaneous bone conduction devices: skin reactions and implant survival. Otol Neurotol. 2012;33:192-198.

9. Kiringoda R, Lustig LR. A Meta-analysis of the complications associated with osseointegrated hearing aids. Otol Neurotol. 2013;34:790-794.

10. Shirazi M, Marzo S, Leonetti J. Perioperative complications with the bone anchored hearing aid. Otolaryngol Head Neck Surg. 2006;134: 236-239.

11. Snik A, Mylanus E, Proops D, et al. Consensus statements on the BAHA system: where do we stand at present? Ann Otol Rhinol Laryngol. 2005;Suppl 195:2-12.

12. Tjellström A, Granström G. Long-term follow-up with the boneanchored hearing aid: a review of the first 100 patients between 1977 and 1985. Ear Nose Throat J. 1994;73(2):112-114.

13. Wazen J, Wycherly B, Daugherty J. Complications of bone-anchored hearing devices. In: Kompis M, Caversaccio M-D. Implantable Bone Conduction Hearing Aids. Basel: Karger Press; 2011:63-72.

14. Hough J, Vernon J, Dormer K, et al. Experiences with implantable hearing devices and a presentation of a new device. Ann Otol Rhinol Laryngol. 1986;95:60-65.

15. Håkansson B, Tjellström A, Carlsson P. Percutaneous vs transcutaneous transducers for hearing by direct bone conduction. Otolaryngol Head Neck Surg. 1990;102:339-344.

16. Håkansson B. The future of bone conduction hearing devices. $A d v$ Otorhinolaryngol. 2011;71:140-152.

17. Hol MK, Cremers CW, Coppens-Schellekens W, Snik AF. The BAHA Softband. A new treatment for young children with bilateral congenital aural atresia. Int J Pediatr Otorhinolaryngol. 2005;69(7):973-980.

18. Verhagen CV, Hol MK, Coppens-Schellenkens W, Snik AF, Cremers CW. The Baha Softband. A new treatment for young children with bilateral congenital aural atresia. Int J Pediatr Otorhinolaryngol. 2008;72(10): $1455-1459$.

19. Doshi J, Sheehan P, McDermott AL. Bone anchored hearing aids in children: an update. Int J Pediatric Otorhinolaryngol. 2012;76:618-622.

20. Zarowski AJ, Verstraeten N, Somers T, Riff D, Offeciers EF. Headbands, testbands and softbands in preoperative testing and application of bone-anchored devices in adults and children. Adv Otorhinolaryngol. 2011;71:124-131.

21. Heywood RL, Patel PM, Jonathan DA. Comparison of hearing thresholds obtained with Baha preoperative assessment tools and those obtained with the osseointegrated implant. Ear Nose Throat J. 2011;90(5):E21-E27.

22. Verstraeten N, Zarowski AJ, Somers T, Riff D, Offeciers EF. Comparison of the audiologic results obtained with the bone-anchored hearing aid attached to the headband, the testband, and to the "snap" abutment. Otol Neurotol. 2009;30(1):70-75.

23. Håkansson B, Tjellström A, Rosenhall U. Hearing thresholds with direct bone conduction versus conventional bone conduction. Scand Audiol. 1984;13:3-13.

24. The Glass Explorer Program [webpage on the internet]. Available from https://www.google.com/glass/start. Accessed November 17, 2014.

25. Siegert R. [Magnetic coupling of partially implantable bone conduction hearing aids without open implants]. Laryngothinootologie. 2010;89(6):346-351. German. 
26. Siegert R. Partially implantable bone conduction hearing aids without a percutaneous abutment (Otomag): technique and preliminary clinical results. Adv Otorhinolaryngol. 2011;71:41-46.

27. Siegert R, Kanderske J. A new semi-implantable transcutaneous bone conduction device: clinical, surgical, and audiologic outcomes in patients with congenital ear canal atresia. Otol Neurotol. 2013;34:927-934.

28. Hol MKS, Nelissen RC, Agterberg MJH, Cremers CWRJ, Snik AFM. Comparison between a new implantable transcutaneous bone conductor and percutaneous bone-conduction hearing implant. Otol Neurotol. 2013;34:1071-1075.

29. Reinfeldt S, Stenfelt S, Good T, Håkansson B. Bone conduction transmission from a sound field estimated by thresholds, ear canal pressure and skull vibrations. J Acoust Soc Am. 2007;121(3):1576-1587.

30. Sylvester DC, Gardner R, Reilly PG, Rankin K, Raine CH. Audiologic and surgical outcomes of a novel, nonpercutaneous, bone conducting hearing implant. Otol Neurotol. 2013;34:922-926.

31. Magliulo G, Turchetta R, Iannella G, di Masino RV, de Vincentiis M. Sophono Alpha System and subtotal petrosectomy with external auditory canal blind sac closure. Eur Arch Otorhinolaryngol. Epub June 8, 2014.

32. O'Niel MB, Runge CL, Friedland DR, Kerschner JE. Patient outcomes in magnet-based implantable auditory assist devices. JAMA Otolaryngol Head Neck Surg. Epub April 24, 2014.

33. Işeri M, Orhan KS, Kara A, et al. A new transcutaneous bone anchored hearing device - the Baha ${ }^{\circledR}$ Attract System: the first experience in Turkey. Kulak Burun Bogaz Ihtis Derg. 2014;24(2):59-64.

34. Kurz A, Flynn M, Caversaccio M, Kompis M. Speech understanding with a new implant technology: a comparative study with a new nonskin penetrating Baha system. Biomed Res Int. 2014;2014:416205.

35. Tjellström A, Håkansson B. The bone-anchored hearing aid. Design principles, indications, and long-term clinical results. Otolaryngol Clin North Am. 1995;28(1):53-72.

36. Kurz A, Caversaccio M, Kompis M. Hearing performance with 2 different high-power sound processors for osseointegrated auditory implants. Otol Neurotol. 2013;34:604-610.

37. Desmet JBJ, Bosman AJ, Snik AFM, et al. Comparison of sound processing strategies for osseointegrated bone conduction implants in mixed hearing loss: multiple-channel nonlinear versus single-channel linear processing. Otol Neurotol. 2013;34:598-603.

38. Kompis M, Kurz A, Pfiffner F, Senn P, Arnold A, Caversaccio M. Is complex signal processing for bone conduction hearing aids useful? Cochlear Implants Int. 2014;15(S1):47-50.

39. Wallberg E, Granström G, Tjellström A, Stahlfors J. Implant survival rate in bone-anchored hearing aid users: long-term results. J Laryngol Otol. 2011;125(11):1131-1135.

40. Dun CA, de Wolf MJ, Hol MK, et al. Stability, survival, and tolerability of a novel baha implant system: six-month data from a multicenter clinical investigation. Otol Neurotol. 2011;32(6):1001-1007.

41. Ivanoff CJ, Sennerby L, Johansson C, Rangert B, Lekholm U. Influence of implant diameters on the integration of screw implants. An experimental study in rabbits. Int J Oral Maxillofac Surg. 1997;26(2): 141-148.

42. Palmquist A, Omar OM, Esposito M, Lausmaa J, Thomsen P. Titanium oral implants: surface characteristics, interface biology and clinical outcome. J R Soc Interface. 2010;7:515-527.

43. de Wolf MJF. Bone Anchored Hearing Aid - clinical outcomes of the linear incision technique and benefit assessment [doctoral thesis]. Netherlands: Radboud University Nijmegen Medical Centre; 2011.

44. Hultcrantz M. Outcome of the bone-anchored hearing aid procedure without skin thinning: a prospective clinical trial. Otol Neurotol. 2011;32(7):1134-1139.

45. Hultcrantz M, Lanis A. A five-year follow-up on the osseointegration of bone-anchored hearing device implantation without tissue reduction. Otol Neurotol. 2014;35(8):1480-1485.

46. van de Berg R, Stokroos RJ, Hof JR, Chenault MN. Bone-anchored hearing aid: a comparison of surgical techniques. Otol Neurotol. 2010;31(1):129-135.
47. Taghavi H, Håkansson B, Reinfeldt S. Analysis and Design of RF power and data link using amplitude modulation of Class-E for a novel bone conduction implant. IEEE Trans Biomed Eng. 2012;59: 3050-3059.

48. Håkansson $\mathrm{B}$. The balanced electromagnetic separation transducer: a new bone conduction transducer. J Acoust Soc Am. 2003;113: 818-825.

49. Eeg-Olofsson M, Håkansson B, Reinfeldt S, et al. The bone conduction implant - first implantation, surgical and audiologic aspects. Otol Neurotol. 2014;35(4):679-685.

50. Reinfeldt S, Håkansson B, Taghavi H, Fredén Jansson KJ, Eeg-Olofsson M. The bone conduction implant - clinical results of the first six patients. Int $J$ Audiol. In press.

51. Håkansson B, Eeg-Olofsson M, Reinfeldt S, Stenfelt S, Granström G. Percutaneous vs transcutaneous bone conduction implant system: a feasibility study on a cadaver head. Otol Neurotol. 2008;29(8): 1132-1139.

52. Håkansson B, Reinfeldt S, Eeg-Olofsson M, et al. A novel bone conduction implant (BCI): Engineering aspects and pre-clinical studies. Int $J$ Audiol. 2010;49:203-215.

53. Eeg-Olofsson M, Stenfelt S, Tjellström A, Granström G. Transmission of bone-conducted sound in the human skull measured by cochlear vibrations. Int J Audiol. 2008;47:761-769.

54. Eeg-Olofsson M, Stenfelt S, Granström G. Implications for contralateral bone-conducted transmission as measured by cochlear vibrations. Otol Neurotol. 2011;32(2):192-198.

55. Taghavi H, Håkansson B, Reinfeldt S, Eeg-Olofsson M, Akhshijan S. Feedback analysis in percutaneous bone-conduction device and bone-conduction implant on a dry cranium. Otol Neurotol. 2012;33: 413-420.

56. Taghavi H, Håkansson B, Eeg-Olofsson M, et al. A vibration investigation of a flat surface contact to skull bone for direct bone conduction transmission in sheep skulls in vivo. Otol Neurotol. 2013;34: 690-698.

57. Eeg-Olofsson M, Lith A, Håkansson B, et al. Evaluation of bone tissue formation in a flat surface attachment of a bone conduction implant - a pilot study in a sheep model. Audiol Neurotol EXTRA. 2014;4:62-76.

58. Reinfeldt S, Håkansson B, Taghavi H, Eeg-Olofsson M. Bone conduction hearing sensitivity in normal-hearing subjects: transcutaneous stimulation at BAHA vs BCI position. Int $J$ Audiol. 2014;53(6): 360-369.

59. Sprinzl G, Lenarz T, Ernst A, et al. First European multicenter results with a new transcutaneous bone conduction hearing implant system: shortterm safety and efficacy. Otol Neurotol. 2013;34(6):1076-1083.

60. Barbara M, Perotti M, Gioia B, Volpini L, Monini S. Transcutaneous bone-conduction hearing device: audiological and surgical aspects in a first series of patients with mixed hearing loss. Acta Otolaryngol. 2013;133(10):1058-1064

61. Manrique M, Sanhueza J, Manrique R, de Abajo J. A new bone conduction implant: surgical technique and results. Otol Neurotol. 2014;35(2): 216-220.

62. Ihler F, Volbersw L, Blum J, Matthias C, Canis M. Preliminary functional results and quality of life after implantation of a new bone conduction hearing device in patients with conductive and mixed hearing loss. Otol Neurotol. 2014;35(2):211-215.

63. Riss D, Arnoldner C, Baumgartner WD, et al. Indication criteria and outcomes with the Bonebridge transcutaneous bone-conduction implant. Laryngoscope. Epub August 20, 2014.

64. Plontke SK, Radetzki F, Seiwerth I, et al. Individual computer-assisted 3D planning for surgical placement of a new bone conduction hearing device. Otol Neurotol. 2014;35: 1251-1257.

65. Lassaletta L, Sanchez-Cuadrado I, Muñoz E, Gavilan J. Retrosigmoid implantation of an active bone conduction stimulator in a patient with chronic otitis media. Auris Nasus Larynx. 2014;41:84-87.

66. Murray M, Popelka GR, Miller R. Efficacy and safety of an in-the mouth bone conduction device for single-sided deafness. Otol Neurotol. 2011;32:437-443. 
67. Murray M, Miller R, Hujoel P, Popelka GR. Long-term safety and benefit of a new intraoral device for single-sided deafness. Otol Neurotol. 2011;32:1262-1269.

68. Gurgel RK, Shelton C. The SoundBite hearing system: patient-assessed safety and benefit study. Laryngoscope. 2013;123(11):2807-2812.

69. Syms MJ, Hernandez KE. Bone conduction hearing: device auditory capability to aid in device selection. Otolaryngol Head Neck Surg. 2014;150(5):866-871.

70. Zwartenkot JW, Snik AFM, Mylanus EAM, Mulder JJS. Amplification options for patients with mixed hearing loss. Otol Neurotol. 2014;35: 221-226

71. Mueller HG, Killion MC. An easy method for calculating the articulation. Hear J. 1990;43:14-17.

72. Stenfelt $\mathrm{S}$, Håkansson B. Air versus bone conduction: an equal loudness investigation. Hear Res. 2002;167(1-2):1-12.

73. Mertens G, Desmet J, Snik A, Heyning P. An experimental objective method to determine maximum output and dynamic range of an active bone conduction implant: the Bonebridge. Otol Neurotol. 2014;35: 1126-1130.
74. Stenfelt S, Reinfeldt S. A model of the occlusion effect with boneconducted stimulation. Int J Audiol. 2007;46(10):595-608.

75. Taghavi H, Håkansson B, Reinfeldt S. A novel bone conduction implant system - analog radio frequency data and power link design. In: Proceeding of the 9th IASTED International Conference on Biomedical Engineering (BioMed 2012), Innsbruck, Austria. 2012:327-335.

76. Eeg-Olofsson M, Stenfelt S, Taghavi H, et al. Transmission of bone conducted sound - correlation between hearing perception and cochlear vibration. Hear Res. 2013;306:11-20.

77. Reinfeldt S, Östli P, Håkansson B, Taghavi H, Eeg-Olofsson M. Study of the feasible size of a bone conduction implant (BCI) transducer in the temporal bone. Otol Neurotol. In press 2014.

78. Fredén Jansson KJ, Håkansson B, Taghavi H, Reinfeldt S, Eeg-Olofsson M. MRI induced torque and demagnetization in retention magnets for bone conduction implants. IEEE Trans Biomed Eng. 2014;61(6):1887-1893.

79. Carlsson P, Håkansson B. The bone-anchored hearing aid: Reference quantities and functional gain. Ear \& Hearing. 1997;18(1):34-41.
Medical Devices: Evidence and Research

\section{Publish your work in this journal}

Medical Devices: Evidence and Research is an international, peerreviewed, open access journal that focuses on the evidence, technology, research, and expert opinion supporting the use and application of medical devices in the diagnosis, treatment and management of clinical conditions and physiological processes. The identification of novel

\section{Dovepress}

devices and optimal use of existing devices which will lead to improved clinical outcomes and more effective patient management and safety is a key feature. The manuscript management system is completely online and includes a quick and fair peer-review system. Visit http://www. dovepress.com/testimonials.php to read real quotes from authors.

Submit your manuscript here: http://www.dovepress.com/medical-devices-evidence-and-research-journal 